\title{
Persistent Dysfunction of Coronary Endothelial Vasomotor Responses is Related to Atheroma Plaque Progression in the Infarct-Related Coronary Artery of AMI Survivors
}

\author{
Takeo Horikoshi, Jun-ei Obata, Takamitsu Nakamura, Daisuke Fujioka, Yosuke Watanabe, \\ Kazuto Nakamura, Kazuhiro Watanabe, Yukio Saito and Kiyotaka Kugiyama
}

Department of Internal Medicine II, University of Yamanashi, Faculty of Medicine, Yamanashi, Japan

Aim: Although coronary endothelial vasomotor dysfunction predicts future coronary events, there are few human studies showing the relationship between endothelial vasomotor dysfunction and atheroma plaque progression in the same coronary artery. This study examined whether endothelial vasomotor dysfunction is related to atheroma plaque progression in the infarct-related coronary artery of ST-segment elevation myocardial infarction (STEMI) survivors using serial assessment of coronary plaque size with intravascular ultrasound (IVUS) and coronary vasomotor responses to acetylcholine $(\mathrm{ACh})$.

Methods: This study included 50 patients with a first acute STEMI due to occlusion of the left anterior descending coronary artery (LAD) and successful reperfusion therapy with percutaneous coronary intervention (PCI). IVUS and vasomotor response to ACh in the LAD were measured within two weeks of acute myocardial infarction (AMI) $\left(1^{\text {st }}\right.$ test) and repeated six months $\left(2^{\text {nd }}\right.$ test $)$ after AMI under optimal anti-atherosclerotic therapies.

Results: Percent atheroma volume (PAV) and total atheroma volume (TAV) in the LAD progressed over six months of follow-up in 18 and 14 patients, respectively. PAV and TAV progression was significantly associated with persistent impairment of epicardial coronary artery dilation and coronary blood flow increase in response to ACh at both the $1^{\text {st }}$ and $2^{\text {nd }}$ tests. PAV and TAV progression had no significant association with traditional risk factors, PCI-related variables, medications, and the coronary vasomotor responses to sodium nitroprusside, an endothelium-independent vasodilator.

Conclusions: Persistent impairment of endothelial vasomotor function in the conduit arterial segment and the resistance arteriole was related to atheromatous plaque progression in the infarct-related coronary arteries of STEMI survivors.

Key words: Coronary atherosclerosis, Coronary endothelial function, Intravascular ultrasound, Myocardial infarction

\section{Introduction}

Previous studies showed that coronary endothelial vasomotor dysfunction predicted coronary events ${ }^{1,2)}$. A decrease in the anti-atherogenic role of endothelium-derived nitric oxide (NO) may explain the association between endothelial dysfunction and coronary events $^{3,4)}$. However, endothelial dysfunction of either a peripheral or coronary artery is regarded as an integrated index of all atherogenic and atheroprotective factors present in an individual patient ${ }^{5)}$. In this sense, systemic atherosclerotic risk burden, rather than a local reduction of endothelial NO, may mediate the relationship between coronary endothelial dysfunction and coronary events. Thus, whether endothelial vasomotor dysfunction is intimately related to plaque pro-

Address for correspondence: Kiyotaka Kugiyama, Department of Internal Medicine II, University of Yamanashi, Faculty of Medicine, 1110 Shimokato, Chuo, 4093898 JAPAN E-mail: kugiyama@yamanashi.ac.jp

Received: November 29, 2018 Accepted for publication: February 28, 2019 
gression in the same coronary artery remains unknown. Also, there are few human studies showing the relationship between endothelial vasomotor dysfunction and atheromatous plaque progression in the same infarct-related coronary artery.

Residual stenosis in the infarct-related coronary artery is associated with a great risk of re-occlusion and may predispose patients to coronary events during follow-up in patients with acute myocardial infarction $(\mathrm{AMI})^{6}$. High risk patients, such as AMI survivors, have severely impaired coronary endothelial function due to systemic atherosclerotic risk burden ${ }^{7-10)}$. In addition, reperfusion and using a drug-eluting stent (DES) exacerbate endothelial dysfunction in the entire tree of the infarct-related coronary artery in AMI survivors ${ }^{11-14)}$. However, endothelial vasomotor dysfunction in the infarct-related coronary arteries at the acute phase of MI is restored over time, as shown in our previous reports ${ }^{11,12)}$. Thus, changeable endothelial dysfunction may confound the relationship between endothelial dysfunction and atherosclerotic plaque in the same infarct-related coronary artery. Using serial measurements with IVUS, this study examined the relationship between endothelial vasomotor dysfunction and residual atherosclerotic plaque progression in the infarct-related coronary artery in new-onset STsegment elevation MI (STEMI) survivors with successful reperfusion therapy.

\section{Methods}

\section{Study Patients}

This prospective study initially enrolled 210 consecutive patients with a first STEMI due to occlusion of a proximal segment of the left anterior descending coronary artery (LAD), who were admitted to Yamanashi University Hospital between January 2008 and December 2017. All patients received emergency coronary angiography and successful reperfusion therapy, within 12 hours of the onset of symptoms, by primary percutaneous coronary intervention (PCI) using IVUS-guided stenting. STEMI diagnosis was based on the presence of each of the following criteria $^{15)}$ : typical chest pain persisting for $\geq 30$ minutes, ST-segment elevation of $\geq 0.2 \mathrm{mV}$ in two or more contiguous leads on a standard 12-lead electrocardiogram (ECG), and creatine kinase-MB $\geq$ two fold of the upper limit of normal or troponin $T>0.1 \mathrm{ng} / \mathrm{mL}$. Among the 210 initially enrolled patients, 132 fulfilled the inclusion criterion of no residual organic stenosis $(\geq 30 \%)$ in the LAD after PCI (Fig. 1 ). The exclusion criteria were as follows: 1) previous PCI in the LAD; 2) previous coronary artery bypass surgery; 3) presence of collaterals to the LAD with Rentrop grade $\geq 2 ; 4$ ) congestive heart failure (New York Heart Association classification IV) at one week after AMI; 5) persistent atrial fibrillation and a paced rhythm; 6) age $>80$ years; 7) myocardial bridge in the LAD; 8) valvular heart diseases (aortic stenosis [aortic valve area $<1.0 \mathrm{~cm}^{2}$ ], aortic regurgitation [Sellers classification III/IV], or mitral regurgitation [Sellers classification III/IV]), secondary hypertension, stroke, renal dysfunction (serum creatinine $>2.0 \mathrm{mg} / \mathrm{dL}$ ), or other serious disease. After applying the exclusion criteria, the study included 63 STEMI patients (Fig. 1). The study also included 20 age- and sex-matched control patients, who were selected from 25 consecutive patients with atypical chest pain and normal coronary angiograms. The control patients served as a reference group for determination of cut-off values of coronary vasomotor dysfunction. Written informed consent was obtained from all patients and control subjects before the study. The ethics committee of Yamanashi University Hospital approved the study, which conformed to the principles outlined in the 1975 Declaration of Helsinki.

\section{Study Protocol}

After emergency coronary angiography with PCI, followed by IVUS (IVUS at the $1^{\text {st }}$ test) on admission, cardiac catheterization, including the coronary vasomotor function test, was repeated after one to two weeks and six months (coronary vasomotor measurements at the $1^{\text {st }}$ and $2^{\text {nd }}$ tests, respectively) after AMI (Fig. 1). The cardiac catheterization six months after AMI included IVUS (IVUS at the $2^{\text {nd }}$ test) (Fig. 1). Also, measuring the coronary vasomotor response was performed only once in all of the control subjects. Vasodilators, including calcium channel blockers, nitrates, and nicorandil were withdrawn more than three days before coronary angiography in patients with AMI and control subjects. Blood samples from a peripheral vein were obtained at one to two weeks ( $1^{\text {st }}$ test) and six months after AMI ( $2^{\text {nd }}$ test). Patients received standard medical treatment after admis$\operatorname{sion}^{16)}$, and this was continued for six months, as outlined in Table 1. The patients followed recommended diet and lifestyle changes throughout the follow-up period.

Measurement of Epicardial Coronary Diameter and Coronary Blood Flow Response to Acetylcholine (ACh) and Sodium Nitroprusside (SNP)

A quantitative coronary angiography was performed as described in our previous reports ${ }^{10-12)}$. After baseline angiography, incremental doses of acetylcholine chloride (ACh, OVISOT, Daiichi Sankyo, Tokyo) $(5,10$ and $50 \mu \mathrm{g} / \mathrm{min})$ were infused directly into the 


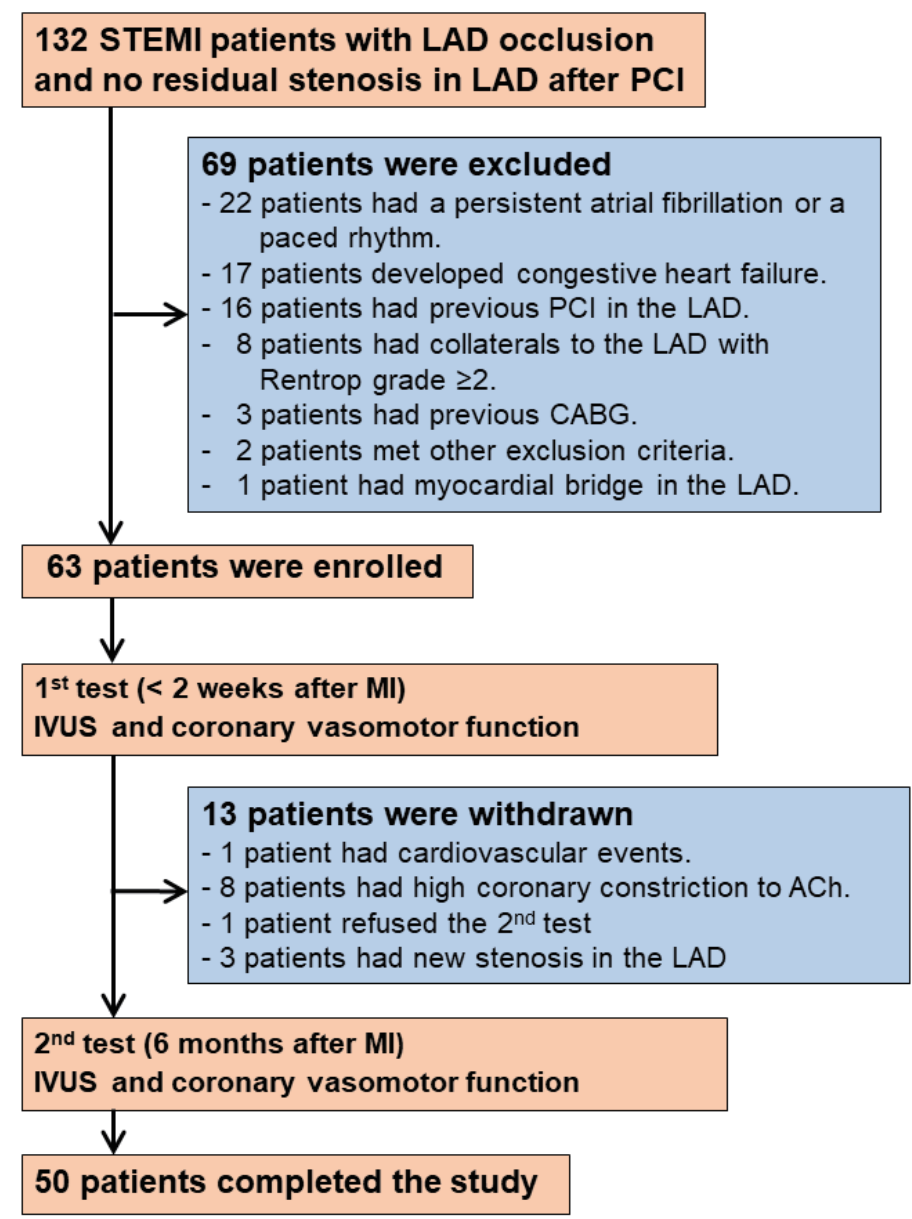

Fig. 1.

A flow chart of the enrollment of patients with acute anterior STEMI. The $1^{\text {st }}$ test was performed $<2$ weeks after MI; the $2^{\text {nd }}$ test was performed 6 months after MI. LAD, left anterior descending coronary artery; PCI, percutaneous coronary intervention; $\mathrm{CABG}$, coronary artery bypass graft.

left coronary artery through the Judkins catheter for 2 min with a 5 -min interval between successive doses. After an additional $15 \mathrm{~min}$, intracoronary sodium nitroprusside (SNP) $(10 \mu \mathrm{g} / \mathrm{min})$ was infused in the same manner as ACh.

To assess the epicardial coronary diameter response to $\mathrm{ACh}$, luminal diameter in a segment 15 $25 \mathrm{~mm}$ from the distal edge of the stent in the LAD was measured quantitatively (Cardio 500, Kontron Instruments, Munich, Germany) before and during each infusion ${ }^{10-12)}$. Each segment analyzed was referenced to a specific anatomic landmark, including the stent for identification, and the analyses at one to two weeks and six months after AMI were examined in parallel to ensure analysis of the identical LAD portion. The luminal diameter at the LAD mid-segments was measured in all of the control subjects in the same manner as in the AMI patients.
Blood flow velocity was measured before and at each infusion using a 0.014 -inch wire equipped with a Doppler crystal at its tip (FloWire, Cardiometrics, Mountain View, California) ${ }^{10-12)}$. The wire was carefully advanced through the Judkins catheter, and the wire tip was positioned in a segment of the LAD 5 $15 \mathrm{~mm}$ from the distal edge of the stent. To calculate flow, the coronary luminal diameter response was also measured in an LAD segment $5-10 \mathrm{~mm}$ distal to the tip of the flow wire before and during each infusion, which was the separate measurement for the epicardial coronary diameter response to $\mathrm{ACh}$ in the $\mathrm{LAD}$, as described above. Coronary blood flow $(\mathrm{mL} / \mathrm{min})$ was estimated from the coronary blood flow velocity and luminal diameter by the following formula: $0.5 \times$ average peak velocity $(\mathrm{cm} / \mathrm{min}) \times$ cross-sectional area $\left(\mathrm{cm}^{2}\right)$, as described previously ${ }^{10-12)}$.

Responses of the coronary artery diameter and 
Table 1. Comparisons of Clinical Characteristics between Patients with and without Progression of Percent Atheroma Volume (PAV) in the Infarct-related Coronary Artery

\begin{tabular}{|c|c|c|c|}
\hline & \multicolumn{3}{|c|}{ PAV progression } \\
\hline & With $(n=18)$ & Without $(n=32)$ & $p$-value \\
\hline Age, years & $64 \pm 8$ & $63 \pm 13$ & 0.77 \\
\hline Sex, male, $n(\%)$ & $14(77.8)$ & $27(84.4)$ & 0.56 \\
\hline Hypertension, $n(\%)$ & $12(66.7)$ & $21(65.6)$ & 0.94 \\
\hline Diabetes mellitus, $n(\%)$ & $3(16.7)$ & $5(15.6)$ & 0.92 \\
\hline \multicolumn{4}{|l|}{ Measurements at the $1^{\text {st }}$ test } \\
\hline BMI $\left(\mathrm{kg} / \mathrm{m}^{2}\right)$ & $24.0 \pm 3.2$ & $24.9 \pm 4.4$ & 0.49 \\
\hline Systolic BP (mmHg) & $104(96-118)$ & $107(100-121)$ & 0.39 \\
\hline $\mathrm{FBG}(\mathrm{mg} / \mathrm{dL})$ & $98(91-113)$ & $97(89-109)$ & 0.88 \\
\hline HbAlc $(\%)$ & $5.9(5.6-6.4)$ & $6.0(5.6-6.2)$ & 0.96 \\
\hline Triglyceride (mg/dL) & $138(112-170)$ & $149(107-184)$ & 0.49 \\
\hline HDL-C $(\mathrm{mg} / \mathrm{dL})$ & $44(38-54)$ & $40(34-45)$ & 0.09 \\
\hline LDL-C (mg/dL) & $142 \pm 25$ & $138 \pm 36$ & 0.74 \\
\hline $\mathrm{CRP}(\mathrm{mg} / \mathrm{dL})$ & $0.5(0.2-0.9)$ & $0.6(0.2-1.7)$ & 0.52 \\
\hline $\mathrm{BNP}(\mathrm{pg} / \mathrm{mL})$ & $63(38-210)$ & $110(31-210)$ & 0.79 \\
\hline LVEF $(\%)$ & $54 \pm 12$ & $56 \pm 10$ & 0.47 \\
\hline \multicolumn{4}{|l|}{ Measurements at the $2^{\text {nd }}$ test } \\
\hline BMI $\left(\mathrm{kg} / \mathrm{m}^{2}\right)$ & $23.9 \pm 3.2$ & $24.7 \pm 4.2$ & 0.49 \\
\hline Systolic BP (mmHg) & $119(107-132)$ & $115(108-125)$ & 0.58 \\
\hline $\mathrm{FBG}(\mathrm{mg} / \mathrm{dL})$ & $97(91-113)$ & $99(90-110)$ & 0.52 \\
\hline HbAlc (\%) & $6.0(5.6-6.2)$ & $6.0(5.7-6.4)$ & 0.68 \\
\hline Triglyceride (mg/dL) & $135(81-205)$ & $126(97-204)$ & 0.97 \\
\hline HDL-C (mg/dL) & $44(37-54)$ & $43(38-50)$ & 0.68 \\
\hline LDL-C (mg/dL) & $83 \pm 18^{*}$ & $86 \pm 28^{*}$ & 0.65 \\
\hline $\mathrm{CRP}(\mathrm{mg} / \mathrm{dL})$ & $0.2(0.1-0.4)^{*}$ & $0.1(0.0-0.1)^{*}$ & 0.37 \\
\hline $\mathrm{BNP}(\mathrm{pg} / \mathrm{mL})$ & $32(20-115)^{*}$ & $25(14-76)^{*}$ & 0.43 \\
\hline $\operatorname{LVEF}(\%)$ & $54 \pm 15$ & $61 \pm 9$ & 0.11 \\
\hline \multicolumn{4}{|l|}{ Risk status at the $1^{\text {st }}$ test, $n(\%)$} \\
\hline Current smoking & $7(38.9)$ & $15(46.9)$ & 0.59 \\
\hline Pts with $\mathrm{BP}<140 / 90$ & $15(83.3)$ & $27(84.4)$ & 0.92 \\
\hline Pts with HbA1c $<7.0 \%$ & $15(83.3)$ & $28(87.5)$ & 0.69 \\
\hline Pts with LDL-C $<100$ & $0(0.0)$ & $4(12.5)$ & 0.12 \\
\hline \multicolumn{4}{|l|}{ Risk status at the $2^{\text {nd }}$ test, $n(\%)$} \\
\hline Current smoking & $0(0.0)$ & $1(3.1)^{*}$ & 0.45 \\
\hline Pts with $\mathrm{BP}<140 / 90$ & $13(72.2)$ & $27(84.4)$ & 0.23 \\
\hline Pts with $\mathrm{HbA} 1 \mathrm{c}<7.0 \%$ & $17(94.4)$ & $28(87.5)$ & 0.43 \\
\hline Pts with LDL-C $<100$ & $13(72.2)^{*}$ & $24(75.0)^{*}$ & 0.94 \\
\hline \multicolumn{4}{|l|}{ Medications at the $1^{\text {st }}$ test, $n(\%)$} \\
\hline Beta-blocker & $10(55.6)$ & $13(40.6)$ & 0.31 \\
\hline ACE-I/ARB & $13(72.2)$ & $22(68.8)$ & 0.80 \\
\hline Statin & $17(94.4)$ & $28(87.5)$ & 0.43 \\
\hline Biganide & $1(5.6)$ & $1(3.1)$ & 0.67 \\
\hline Aspirin & $18(100)$ & $32(100)$ & - \\
\hline Thienopyridines & $18(100)$ & $32(100)$ & - \\
\hline \multicolumn{4}{|l|}{ Medications at the $2^{\text {nd }}$ test, $n(\%)$} \\
\hline Beta-blocker & $9(50.0)$ & $15(46.9)$ & 0.83 \\
\hline ACE-I/ARB & $15(83.3)$ & $24(75.0)$ & 0.50 \\
\hline Statin & $18(100)$ & $30(93.8)$ & 0.28 \\
\hline Biganide & $1(5.6)$ & $1(3.1)$ & 0.67 \\
\hline Aspirin & $18(100)$ & $31(96.9)$ & 0.45 \\
\hline Thienopyridines & $18(100)$ & $32(100)$ & - \\
\hline \multicolumn{4}{|l|}{ AMI variables } \\
\hline Peak CPK (IU/L) & $2471 \pm 1889$ & $3340 \pm 2310$ & 0.22 \\
\hline Use of BMS, $n(\%)$ & $4(22.2)$ & $7(21.9)$ & 0.98 \\
\hline Use of $1^{\text {st }}$ generation DES, $n(\%)$ & $3(16.7)$ & $5(15.6)$ & 0.92 \\
\hline Use of $2^{\text {nd }}$ generation DES, $n(\%)$ & $11(61.1)$ & $20(62.5)$ & 0.98 \\
\hline Stent length $(\mathrm{mm})$ & $28.9 \pm 14$ & $23.1 \pm 9.8$ & 0.13 \\
\hline MLD after stenting (mm) & $2.9 \pm 0.5$ & $3.1 \pm 0.4$ & 0.40 \\
\hline
\end{tabular}

Data are expressed as the mean \pm S.D, median $\left(25\right.$ th -75 th percentiles) or the number $(\%)$ of patients. ${ }^{*} p<0.05$ vs. the respective value at the $1^{\text {st }}$ test. PAV, percent atheroma volume; Pts, patients; BMI, body mass index; BP, blood pressure; FBG, fasting blood glucose; HDL-C, highdensity lipoprotein cholesterol; LDL-C, low-density lipoprotein cholesterol; BNP, brain natriuretic peptide; CRP, C-reactive protein; LVEF, left ventricular ejection fraction; ACE-I, angiotensin converting enzyme inhibitor; ARB, angiotensin II receptor blocker; AMI, acute myocardial infarction; CPK, creatine phosphokinase; PCI, percutaneous coronary intervention; BMS, bare metal stent; DES, drug eluting stent; MLD, minimal lumen diameter. 


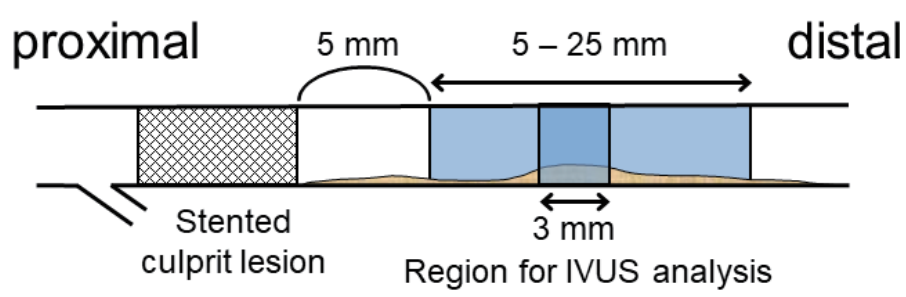

Fig. 2.

A schematic representation of the coronary segments used for intravascular ultrasound (IVUS) analysis. The study analyzed a 3-mm segment with the greatest plaque located within a $5-25 \mathrm{~mm}$ segment that started $5 \mathrm{~mm}$ distal to the distal edge of the stent in the infarct-related coronary artery (LAD).

coronary blood flow to ACh and SNP infusions were expressed as percent changes from their respective baseline values taken just before each infusion. These measurements were performed by two observers (Y. W., K. W.) blinded to the study protocol and patient's clinical characteristics. Measurements of the percent changes in coronary diameter and coronary blood flow in response to ACh $(10 \mu \mathrm{g} / \mathrm{min})$ from the respective baseline values by the two independent observers were highly reproducible $(r=0.98$ and 0.97 , mean difference: $0.91 \pm 0.04 \%$ and $2.9 \pm 0.4 \%$, respectively).

Determination of the Epicardial Coronary Diameter and Coronary Blood Flow Response to ACh in Each Patient and the Cut-Off Values of Impairment of Their Vasomotor Responses

Coronary vasomotor responses to $\mathrm{ACh}$ were determined by the net balance between dilation induced mainly by endothelium-derived NO and constriction mediated by muscarinic receptors in coronary smooth muscle. This balance is altered by the dose of $\mathrm{ACh}$ injected ${ }^{10-12)}$. In this study, the greatest dilator response from baseline among the responses to $3 \mathrm{ACh}$ doses $(5,10$ and $50 \mu \mathrm{g} / \mathrm{min})$ was selected as the epicardial coronary vasomotor response to ACh for each patient and control subject. The epicardial coronary response with the least constriction from baseline among the $3 \mathrm{ACh}$ doses was selected for each patient who did not have a dilator response to any ACh dose. Similarly, the greatest increase in coronary flow response from baseline among the $3 \mathrm{ACh}$ doses was selected as the coronary flow response to $\mathrm{ACh}$ for each patient and control subject. The coronary vasomotor dysfunction cut-off values in response to $\mathrm{ACh}$ were arbitrarily defined as the lower $10 \%$ of the distribution of coronary vasomotor responses to ACh in control subjects. The yield was $4.9 \%$ dilation from baseline for the epicardial coronary dilator response and $133 \%$ increase from baseline for coronary flow response in control subjects.
Intravascular Ultrasound (IVUS) Image Acquisition After intracoronary administration of nitroglycerin, the IVUS catheter was positioned in the distal LAD segment and withdrawn to the coronary ostium using automated pullback at $0.5 \mathrm{~mm} / \mathrm{sec}$ using 40-MHz IVUS imaging catheters (Galaxy 2, Boston Scientific Corporation, Natick, MA) ${ }^{17)}$. The volumetric IVUS analyses were performed with a computerized planimetry program (EchoPlaque 3.0, INDEC System, Inc., Mountain View, CA) by an independent examiner blinded to the patients' clinical characteristics ${ }^{17)}$. The study analyzed the $3 \mathrm{~mm}$ segment with the greatest plaque located within a $5-25 \mathrm{~mm}$ segment that started $5 \mathrm{~mm}$ distal to the LAD's distal stent edge (Fig.2). External elastic membrane (EEM) and lumen areas were obtained in every frame $(0.1 \mathrm{~mm}$ thickness) by manual contour detection. The percent atheroma volume (PAV) of the plaque with the $3-\mathrm{mm}$ segment was calculated as $\Sigma$ (EEM cross-section area (CSA) lumen CSA) divided by $\Sigma$ EEM CSA and multiplied by 100 . The total atheroma volume (TAV) of the plaque with the $3-\mathrm{mm}$ segment was calculated as $\Sigma$ (EEM CSA - lumen CSA). Each analyzed segment was referenced to a specific anatomic landmark, including the stent for identification. IVUS analyses at admission and six months after AMI were examined in parallel. The exact distance of the targeted segment from the distal edge of the stent was recorded as a landmark on the longitudinal image of IVUS in each patient to ensure that the same targeted segment was measured at the $1^{\text {st }}$ and $2^{\text {nd }}$ tests. Measurements of the PAV and TAV by the two independent observers (D.F., K.N.) were highly reproducible $(r=0.98$ and 0.98 , mean difference: $0.28 \pm 1.16 \%$ and $0.40 \pm 1.22 \mathrm{~mm}^{3}$, respectively).

\section{Statistical Analysis}

Data are expressed as either the mean $\pm S D$, median and interquartile range $(25$ th and 75 th percentile), or frequencies (\%). Continuous variables 
were compared using Student's paired or unpaired $t$-test, as appropriate. The Shapiro-Wilk test showed that systolic blood pressure (BP), fasting blood glucose (FBG), hemoglobin A1c (HbA1c), triglyceride, highdensity lipoprotein cholesterol (HDL-C), C-reactive protein (CRP), and brain natriuretic peptide (BNP) were not distributed normally. Therefore, these variables were expressed as the median and interquartile range (25th and 75th percentiles), and were compared after log-transformation. Categorical variables between two groups were compared using a chi-square analysis or Fisher's exact test. Correlation between two groups was examined using linear regression analysis. Logistic regression analysis was used to associate coronary plaque volume progression with coronary vasomotor function and the other clinical data. Statistical significance was defined as $p<0.05$. Analyses were assessed in part using STATA 10.0 (StataCorp, College Station, TX, USA).

Based on our preliminary observations in the STEMI patients who had LAD occlusion and successful reperfusion therapy, the progression of PAV during the six-month follow-up period occurred in approximately $50 \%$ of patients with impaired endothelial flow response to ACh in the LAD at both $1^{\text {st }}$ and $2^{\text {nd }}$ tests, and in $5 \%$ of the remaining patients. To provide our two-sided statistical analyses with sufficient statistical power of $0.90(\beta=0.10$ and $\alpha=0.05), 46$ patients with STEMI were required to show the statistically significant difference in the prevalence of PAV progression between patients with and without persistent impairment of coronary flow response to ACh at both the $1^{\text {st }}$ and $2^{\text {nd }}$ tests. Sixty-three patients provided this study with sufficient statistical power.

\section{Results}

\section{Study Patients}

Sixty-three patients were finally included in this study, and they had the $1^{\text {st }}$ test (Fig. 1). Among them, 13 patients were withdrawn from the study after the $1^{\text {st }}$ test (Fig. 1 ), as one patient had a cardiovascular event between the $1^{\text {st }}$ and $2^{\text {nd }}$ tests, eight had a high constrictor response ( $>30 \%$ from baseline) of the epicardial segment to $\mathrm{ACh}$ at the $1^{\text {st }}$ test, and one refused to take the $2^{\text {nd }}$ test. Three had new angiographic organic stenosis $(>30 \%)$ in the lesion proximal to the proximal edge of the stent at the $2^{\text {nd }}$ test. Moderate stenosis $(>30 \%)$ in the conduit coronary artery might affect an increase in coronary blood flow ${ }^{18)}$. The remaining 50 patients completed both the $1^{\text {st }}$ and $2^{\text {nd }}$ tests (Fig. 1). This study finally analyzed the 50 patients who completed the study protocol (Fig.1). Their clinical characteristics are shown in Table 1.
Comparison of Clinical Parameters between Patients with and without Progression of PAV or TAV

As a whole, patients' PAV and TAV at the target lesion decreased over six months (PAV, $41.1 \pm 12.7 \%$ at the $1^{\text {st }}$ test vs. $38.6 \pm 12.0 \%$ at the $2^{\text {nd }}$ test, $p=0.02$; TAV, $13.6 \pm 8.1 \mathrm{~mm}^{3}$ at the $1^{\text {st }}$ test vs. $11.7 \pm 7.0 \mathrm{~mm}^{3}$ at the $2^{\text {nd }}$ test, $\left.p<0.01\right)$ (Fig. 3). However, PAV and TAV increased over six months in 18 and 14 patients, respectively (Tables 2 and 3). There was no significant difference in traditional risk factors, the rate of achievement of risk factors' target levels, medication use at the $1^{\text {st }}$ and $2^{\text {nd }}$ tests, or PCI-related variables between patients with and without progression of PAV or TAV (Table 1 and Supplemental Table 1). LDL-C and BNP levels significantly decreased from the $1^{\text {st }}$ to the $2^{\text {nd }}$ test in both patients with and without progression of PAV or TAV (Table 1 and Supplemental Table 1). The prevalence of current smoking was reduced, and the number of patients with LDL-C levels $<100 \mathrm{mg} / \mathrm{dL}$ increased from the $1^{\text {st }}$ to the $2^{\text {nd }}$ test in both patients with and without progression of PAV or TAV (Table 1 and Supplemental Table 1).

Comparison of Coronary Vasomotor Functions and IVUS Parameters between Patients with and without Progression of PAV or TAV

The responses of epicardial coronary diameter and coronary flow to ACh, but not SNP, improved significantly from the $1^{\text {st }}$ to the $2^{\text {nd }}$ test in patients without progression of PAV or TAV (Tables 2 and 3). The epicardial coronary diameter and coronary flow responses to $\mathrm{ACh}$ at the $1^{\text {st }}$ test were similar between patients with and without progression of PAV or TAV (Tables 2 and 3). The vasomotor responses to ACh at the $2^{\text {nd }}$ test were significantly lower in patients with progression of TAV (Table 3). The vasomotor responses to $\mathrm{ACh}$ at the $2^{\text {nd }}$ test tended to be lower in patients with progression of PAV, but there was no statistical significance (Table 2). The coronary vasomotor responses to SNP at either the $1^{\text {st }}$ or $2^{\text {nd }}$ test were comparable between patients with and without PAV or TAV progression (Tables 2 and 3). The baseline coronary diameter and flow before the injection of ACh or SNP were similar between the $1^{\text {st }}$ and $2^{\text {nd }}$ tests in patients with and without progression of PAV or TAV (Tables 2 and 3). Pre-existing PAV and TAV of the coronary lesion at the $1^{\text {st }}$ test were similar between patients with and without progression of PAV or TAV (Tables 2 and 3 ).

Logistic Regression Analysis for Association of Progression of PAV and TAV with Traditional Risk Factors, Coronary Vasomotor Function, and Their Changes

The progression of PAV or TAV over six months 


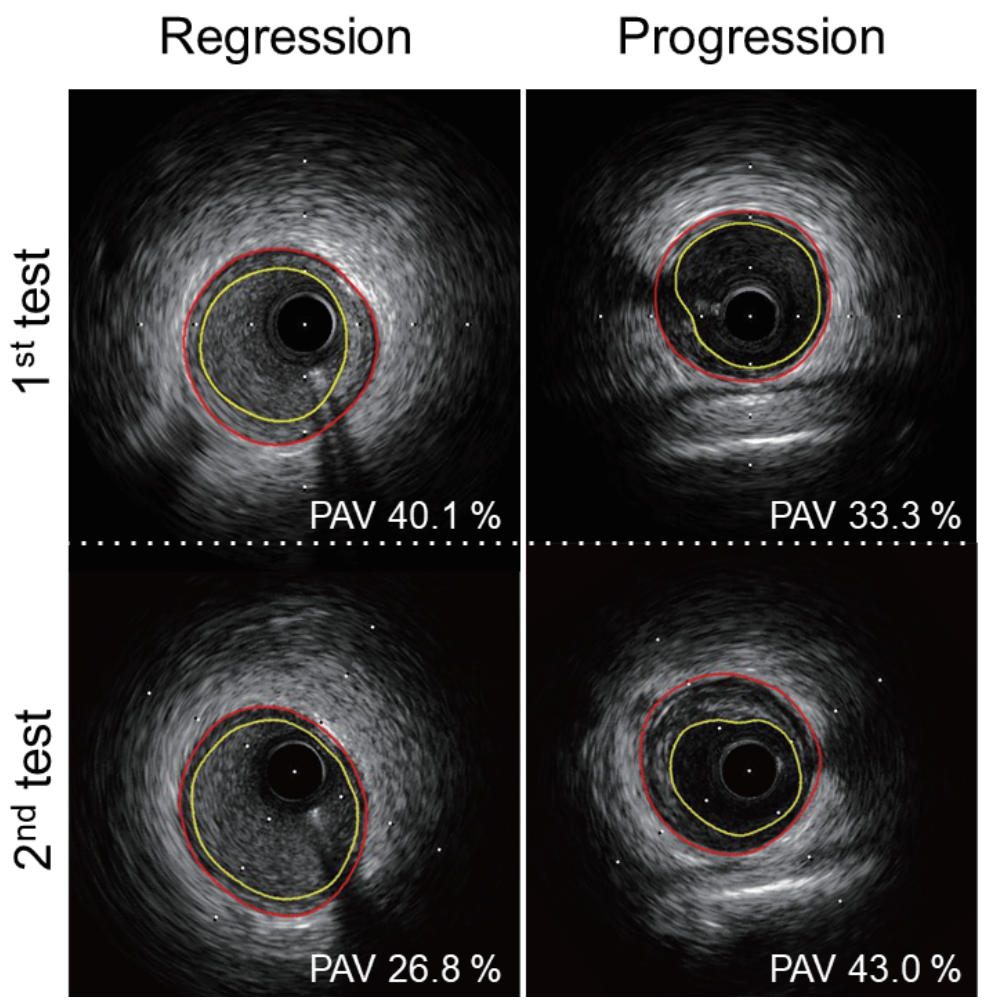

Fig. 3.

Representative IVUS images of PAV with regression (left panels) and images of PAV with progression (right panels) from the $1^{\text {st }}$ to the $2^{\text {nd }}$ tests. Yellow line indicates lumen; red line indicates the boundary of the lamina elastica externa.

Table 2. Comparisons of Epicardial Coronary Diameter and Coronary Blood Flow at Baseline, Their Responses to ACh and SNP, and IVUS Parameters between Patients with and without PAV Progression in the Infarct-related Coronary Arteries

\begin{tabular}{|c|c|c|c|}
\hline & \multicolumn{2}{|c|}{ PAV progression } & \multirow[b]{2}{*}{$p$-value } \\
\hline & With $(n=18)$ & Without $(n=32)$ & \\
\hline \multicolumn{4}{|l|}{ Responses to $\mathrm{ACh}(\%)$} \\
\hline Coronary diameter at the $1^{\text {st }}$ test & $2.5 \pm 12.0$ & $-1.1 \pm 10.9$ & 0.28 \\
\hline Coronary diameter at the $2^{\text {nd }}$ test & $6.7 \pm 18.1$ & $14.8 \pm 11.4^{*}$ & 0.10 \\
\hline Coronary flow at the $1^{\text {st }}$ test & $99 \pm 95$ & $83 \pm 70$ & 0.49 \\
\hline Coronary flow at the $2^{\text {nd }}$ test & $159 \pm 150$ & $199 \pm 113^{*}$ & 0.28 \\
\hline \multicolumn{4}{|l|}{ Responses to SNP (\%) } \\
\hline Coronary diameter at the $1^{\text {st }}$ test & $15.2 \pm 8.1$ & $14.9 \pm 9.2$ & 0.91 \\
\hline Coronary diameter at the $2^{\text {nd }}$ test & $22.0 \pm 16.7$ & $17.5 \pm 10.7$ & 0.26 \\
\hline Coronary flow at the $1^{\text {st }}$ test & $108 \pm 90$ & $144 \pm 117$ & 0.26 \\
\hline Coronary flow at the $2^{\text {nd }}$ test & $182 \pm 129$ & $147 \pm 98$ & 0.29 \\
\hline \multicolumn{4}{|l|}{ Baseline measurements before $\mathrm{ACh}$ injection } \\
\hline Coronary diameter at the $1^{\text {st }}$ test $(\mathrm{mm})$ & $1.6 \pm 0.2$ & $1.7 \pm 0.3$ & 0.06 \\
\hline Coronary diameter at the $2^{\text {nd }}$ test $(\mathrm{mm})$ & $1.6 \pm 0.4$ & $1.7 \pm 0.3$ & 0.07 \\
\hline Coronary flow at the $1^{\text {st }}$ test $(\mathrm{mL} / \mathrm{min})$ & $21 \pm 9$ & $24 \pm 9$ & 0.28 \\
\hline Coronary flow at the $2^{\text {nd }}$ test $(\mathrm{mL} / \mathrm{min})$ & $19 \pm 11$ & $25 \pm 12$ & 0.10 \\
\hline \multicolumn{4}{|l|}{ IVUS measurements } \\
\hline Vessel volume at the $1^{\text {st }}$ test $\left(\mathrm{mm}^{3}\right)$ & $31.3 \pm 19.3$ & $32.4 \pm 10.1$ & 0.79 \\
\hline Vessel volume at the $2^{\text {nd }}$ test $\left(\mathrm{mm}^{3}\right)$ & $28.4 \pm 18.5$ & $30.4 \pm 10.2$ & 0.60 \\
\hline Lumen volume at the $1^{\text {st }}$ test $\left(\mathrm{mm}^{3}\right)$ & $19.2 \pm 11.3$ & $18.0 \pm 6.3$ & 0.56 \\
\hline Lumen volume at the $2^{\text {nd }}$ test $\left(\mathrm{mm}^{3}\right)$ & $16.4 \pm 10.3$ & $18.9 \pm 7.4$ & 0.42 \\
\hline PAV at the $1^{\text {st }}$ test $(\%)$ & $36.5 \pm 10.6$ & $43.8 \pm 13.3$ & 0.06 \\
\hline PAV at the $2^{\text {nd }}$ test $(\%)$ & $40.6 \pm 10.8^{*}$ & $37.5 \pm 12.7^{*}$ & 0.39 \\
\hline
\end{tabular}

Data are expressed as the mean \pm S.D. ${ }^{*} p<0.05$ vs. the respective value at the $1^{\text {st }}$ test. SNP, sodium nitroprusside; IVUS, intravascular ultrasound; other abbreviations are as in Table 1. 
Table 3. Comparisons of Epicardial Coronary Diameter and Coronary Blood Flow at Baseline, Their Responses to ACh and SNP, and IVUS Parameters between Patients with and without TAV Progression in the Infarct-related Coronary Arteries

\begin{tabular}{|c|c|c|c|}
\hline & \multicolumn{2}{|c|}{ TAV progression } & \multirow[b]{2}{*}{$p$-value } \\
\hline & With $(n=14)$ & Without $(n=36)$ & \\
\hline \multicolumn{4}{|l|}{ Responses to ACh (\%) } \\
\hline Coronary diameter at the $1^{\text {st }}$ test & $-0.9 \pm 12.5$ & $0.6 \pm 11.0$ & 0.68 \\
\hline Coronary diameter at the $2^{\text {nd }}$ test & $2.3 \pm 15.6$ & $15.6 \pm 12.4^{*}$ & $<0.01$ \\
\hline Coronary flow at the $1^{\text {st }}$ test & $93 \pm 100$ & $87 \pm 71$ & 0.80 \\
\hline Coronary flow at the $2^{\text {nd }}$ test & $114 \pm 94$ & $212 \pm 129^{*}$ & 0.01 \\
\hline \multicolumn{4}{|l|}{ Responses to SNP (\%) } \\
\hline Coronary diameter at the $1^{\text {st }}$ test & $12.9 \pm 5.2$ & $15.8 \pm 9.7$ & 0.31 \\
\hline Coronary diameter at the $2^{\text {nd }}$ test & $19.0 \pm 15.8$ & $19.2 \pm 12.3$ & 0.97 \\
\hline Coronary flow at the $1^{\text {st }}$ test & $104 \pm 69$ & $142 \pm 119$ & 0.17 \\
\hline Coronary flow at the $2^{\text {nd }}$ test & $133 \pm 85$ & $171 \pm 118$ & 0.28 \\
\hline \multicolumn{4}{|l|}{ Baseline measurements before $\mathrm{ACh}$ injection } \\
\hline Coronary diameter at the $1^{\text {st }}$ test $(\mathrm{mm})$ & $1.6 \pm 0.3$ & $1.7 \pm 0.3$ & 0.51 \\
\hline Coronary diameter at the $2^{\text {nd }}$ test $(\mathrm{mm})$ & $1.6 \pm 0.4$ & $1.6 \pm 0.4$ & 0.41 \\
\hline Coronary flow at the $1^{\text {st }}$ test $(\mathrm{mL} / \mathrm{min})$ & $22 \pm 8$ & $23 \pm 10$ & 0.91 \\
\hline Coronary flow at the $2^{\text {nd }}$ test $(\mathrm{mL} / \mathrm{min})$ & $20 \pm 10$ & $24 \pm 12$ & 0.39 \\
\hline \multicolumn{4}{|l|}{ IVUS measurements } \\
\hline Vessel volume at the $1^{\text {st }}$ test $\left(\mathrm{mm}^{3}\right)$ & $27.0 \pm 20.6$ & $33.9 \pm 10.0$ & 0.10 \\
\hline Vessel volume at the $2^{\text {nd }}$ test $\left(\mathrm{mm}^{3}\right)$ & $28.6 \pm 20.0$ & $30.1 \pm 10.5$ & 0.69 \\
\hline Lumen volume at the $1^{\text {st }}$ test $\left(\mathrm{mm}^{3}\right)$ & $17.2 \pm 14.0$ & $19.1 \pm 6.1$ & 0.52 \\
\hline Lumen volume at the $2^{\text {nd }}$ test $\left(\mathrm{mm}^{3}\right)$ & $17.7 \pm 13.4$ & $18.3 \pm 6.8$ & 0.88 \\
\hline TAV at the $1^{\text {st }}$ test $\left(\mathrm{mm}^{3}\right)$ & $10.1 \pm 8.4$ & $14.9 \pm 7.7$ & 0.06 \\
\hline TAV at the $2^{\text {nd }}$ test $\left(\mathrm{mm}^{3}\right)$ & $11.3 \pm 8.5^{*}$ & $11.8 \pm 6.5^{*}$ & 0.82 \\
\hline
\end{tabular}

Data are expressed as the mean \pm S.D. ${ }^{*} p<0.05$ vs. the respective value at the $1^{\text {st }}$ test. Other abbreviations are the same as in Tables 1 and 2.

had no significant association with traditional risk factors at either the $1^{\text {st }}$ or $2^{\text {nd }}$ test (Table 4). The epicardial coronary diameter and coronary flow responses to $\mathrm{ACh}$ at the $2^{\text {nd }}$ test were significantly associated with progression of TAV. In contrast, the responses to ACh at the $1^{\text {st }}$ test were not significantly associated with PAV and TAV progression. The epicardial coronary diameter and flow responses to SNP at both the $1^{\text {st }}$ and $2^{\text {nd }}$ tests were not associated with progression of PAV or TAV. We classified patients into two groups according to the epicardial coronary diameter response to ACh: patients who had epicardial coronary vasomotor dysfunction at both the $1^{\text {st }}$ and $2^{\text {nd }}$ tests (persistently impaired group); and patients who had epicardial vasomotor dysfunction at either the $1^{\text {st }}$ or the $2^{\text {nd }}$ test, or neither of the two tests (other group). Similarly, patients were classified to the two groups according to their coronary flow response to ACh. The progression of PAV or TAV over six months was significantly associated with persistent impairment of epicardial coronary diameter and the coronary flow responses to ACh (Table 4).
Linear Correlation of the Percent Changes in PAV and TAV with the Difference in Epicardial Coronary Diameter and Coronary Flow Responses to ACh from the $1^{\text {st }}$ to the $2^{\text {nd }}$ test

The change in PAV or TAV over six months had a significant inverse correlation with the difference in epicardial coronary diameter and coronary flow response to $\mathrm{ACh}$ from the $1^{\text {st }}$ to $2^{\text {nd }}$ test (Fig.4). In contrast, the changes in PAV or TAV over six months had no significant correlation with the difference in the coronary responses to SNP between the $1^{\text {st }}$ and $2^{\text {nd }}$ tests (changes in PAV, $r=-0.06$ and 0.11 , respectively, with the difference in epicardial coronary diameter and flow response; changes in TAV, $r=-0.06$ and 0.01 , respectively, with the difference in epicardial coronary diameter and flow response).

\section{Discussion}

The present study showed that the percent changes in PAV or TAV over six months of follow-up were inversely correlated with the changes in epicardial coronary diameter and coronary flow responses to 
Horikoshi et al.

Table 4. Logistic Regression Analysis for Association of Progression of PAV and TAV with Clinical Parameters

\begin{tabular}{|c|c|c|c|c|}
\hline & \multicolumn{2}{|c|}{ PAV progression } & \multicolumn{2}{|c|}{ TAV progression } \\
\hline & OR (95\% CI) & $p$-value & OR $(95 \% \mathrm{CI})$ & $p$-value \\
\hline Age & $1.01(0.96-1.06)$ & 0.76 & $1.00(0.95-1.06)$ & 0.99 \\
\hline Male gender & $1.54(0.36-6.68)$ & 0.56 & $4.44(0.98-20.09)$ & 0.06 \\
\hline DES & $1.02(0.25-4.10)$ & 0.98 & $1.66(0.40-6.88)$ & 0.49 \\
\hline Hypertension & $0.96(0.28-3.24)$ & 0.94 & $0.71(0.19-2.71)$ & 0.61 \\
\hline Diabetes mellitus & $0.93(0.19-4.43)$ & 0.93 & $0.59(0.12-2.89)$ & 0.51 \\
\hline Current smoking at the $1^{\text {st }}$ test & $1.39(0.43-4.49)$ & 0.59 & $1.61(0.45-5.76)$ & 0.46 \\
\hline LDL-C at the $1^{\text {st }}$ test & $1.00(0.99-1.02)$ & 0.73 & $0.99(0.97-1.01)$ & 0.41 \\
\hline LDL-C at the $2^{\text {nd }}$ test & $0.99(0.97-1.02)$ & 0.64 & $0.99(0.97-1.02)$ & 0.55 \\
\hline BNP at the $1^{\text {st }}$ test & $0.99(0.98-1.01)$ & 0.65 & $1.01(0.99-1.01)$ & 0.21 \\
\hline BNP at the $2^{\text {nd }}$ test & $1.00(0.99-1.01)$ & 0.99 & $1.01(0.99-1.01)$ & 0.10 \\
\hline CRP at the $1^{\text {st }}$ test & $0.60(0.27-1.33)$ & 0.21 & $0.91(0.59-1.41)$ & 0.68 \\
\hline CRP at the $2^{\text {nd }}$ test & $1.04(0.74-1.47)$ & 0.38 & $1.11(0.79-1.57)$ & 0.54 \\
\hline \multicolumn{5}{|l|}{ Responses to $\mathrm{ACh}$} \\
\hline Coronary diameter at the $1^{\text {st }}$ test & $1.03(0.98-1.09)$ & 0.28 & $0.99(0.94-1.04)$ & 0.68 \\
\hline Coronary diameter at the $2^{\text {nd }}$ test & $0.96(0.92-1.01)$ & 0.07 & $0.93(0.87-0.98)$ & $<0.01$ \\
\hline Coronary flow at the $1^{\text {st }}$ test & $1.00(0.99-1.01)$ & 0.49 & $1.00(0.99-1.01)$ & 0.79 \\
\hline Coronary flow at the $2^{\text {nd }}$ test & $0.99(0.98-1.01)$ & 0.28 & $0.99(0.98-0.99)$ & 0.02 \\
\hline \multicolumn{5}{|l|}{ Responses to SNP } \\
\hline Coronary diameter at the $1^{\text {st }}$ test & $1.00(0.94-1.08)$ & 0.90 & $0.96(0.89-1.04)$ & 0.31 \\
\hline Coronary diameter at the $2^{\text {nd }}$ test & $1.03(0.98-1.07)$ & 0.25 & $0.99(0.95-1.05)$ & 0.97 \\
\hline Coronary flow at the $1^{\text {st }}$ test & $1.00(0.99-1.01)$ & 0.26 & $0.99(0.99-1.01)$ & 0.27 \\
\hline Coronary flow at the $2^{\text {nd }}$ test & $1.00(0.99-1.01)$ & 0.29 & $0.99(0.99-1.01)$ & 0.28 \\
\hline \multicolumn{5}{|c|}{ Persistent impairment of responses to $\mathrm{ACh}$} \\
\hline Coronary diameter & $6.15(1.35-28.13)$ & 0.02 & $6.00(1.36-26.45)$ & 0.02 \\
\hline Coronary flow & $4.33(1.20-15.61)$ & 0.03 & $5.52(1.44-21.14)$ & 0.01 \\
\hline
\end{tabular}

OR, odds ratio; CI, confidence interval; other abbreviations as the same as in Tables 1-3.

ACh, but not SNP, an endothelium-independent vasodilator, in the infarct-related coronary artery in the STEMI patients. In addition, the progression of PAV and TAV was associated with persistently impaired coronary vasomotor responses to ACh. This is the first study to show that persistently impaired endothelial vasomotor function was related to atheroma plaque progression in the entire infarct-related coronary artery tree of STEMI survivors. The longer endothelial dysfunction persisted, the greater the progression of atherosclerotic plaque in the infarct-related coronary artery of STEMI survivors.

Endothelial vasomotor function at baseline $\left(1^{\text {st }}\right.$ test) did not predict plaque progression in the infarctrelated coronary artery in the present study. A single assessment of endothelial vasomotor function may not necessarily reflect later atherosclerotic risk burden in the coronary artery because anti-atherosclerotic treatments were initiated after MI onset. In addition, reperfusion injury and DES transiently exacerbate endothelial dysfunction at baseline ${ }^{11,12)}$. Changeable endothelial function after the baseline measurement may explain the association of coronary plaque progression with the change in the endothelial vasomotor function over time, but not with the baseline endothelial function in the infarct-related coronary artery in the present study. Coronary arterial remodeling affects the measurement of PAV but not TAV. Coronary vasomotor responses similarly related to PAV and TAV, a marker of coronary atherosclerotic burden, which may strengthen our hypothesis that coronary endothelial dysfunction is related to the progression of coronary atherosclerotic burden.

The present study showed that systemic atherosclerotic risk burden at both the $1^{\text {st }}$ and $2^{\text {nd }}$ tests was not associated with coronary plaque progression over six months, a relatively short follow-up period, in the infarct-related coronary artery. Thus, the systemic atherosclerotic risk burden was unlikely to mediate the relationship between coronary endothelial dysfunction and plaque progression in the infarct-related coronary artery in STEMI survivors. Although the traditional atherosclerotic risk factors were not appropriately treated in some study patients, the rate of target level 

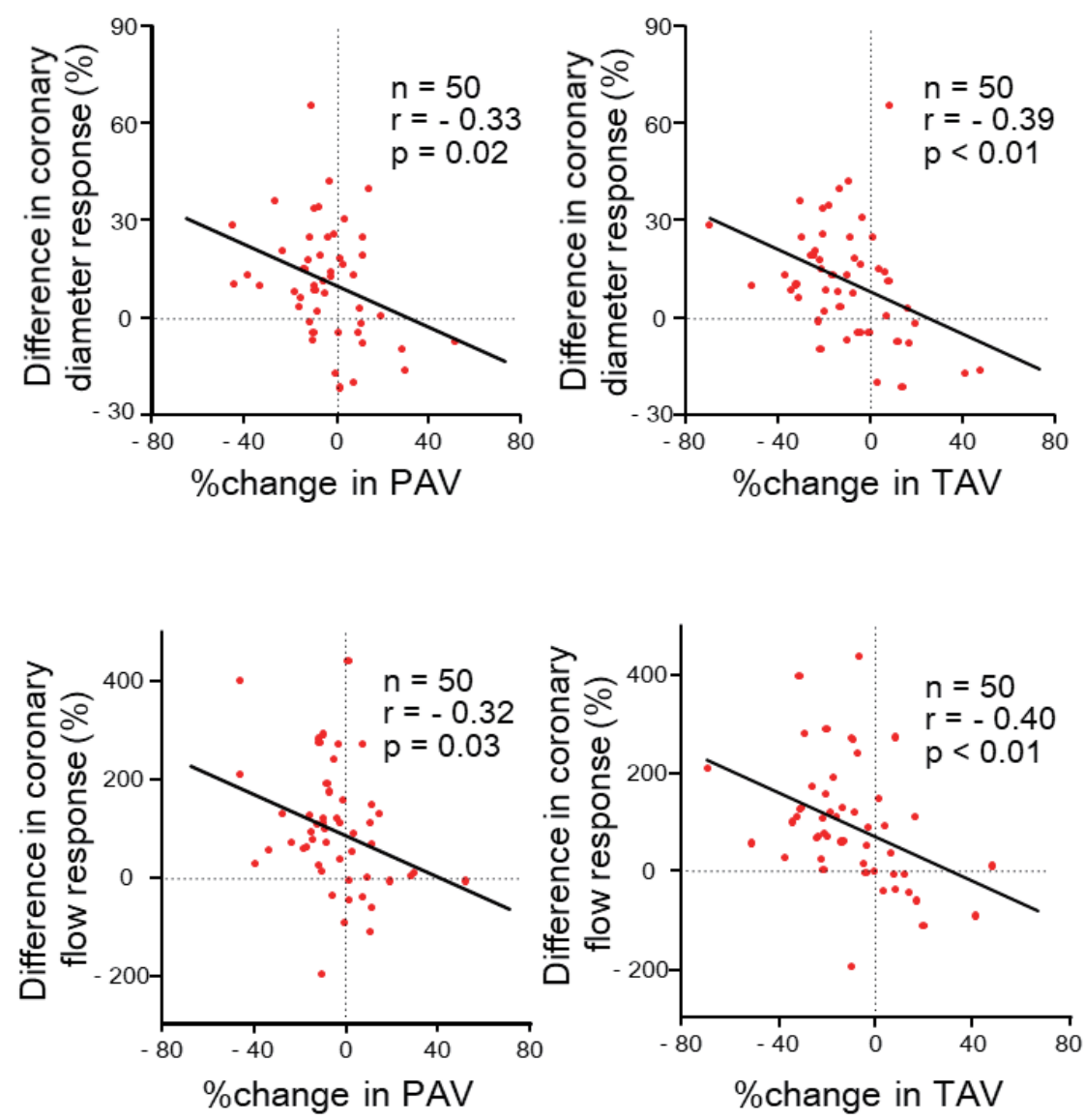

Fig. 4 .

Correlations of the percent changes in PAV (left panels) and TAV (right panels) over six months from the $1^{\text {st }}$ to $2^{\text {nd }}$ test with the difference in responses of epicardial coronary diameter (upper panels) and coronary flow (lower panels) to ACh from the $1^{1 \text { st }}$ to the $2^{\text {nd }}$ test.

achievement of the risk factors and the atherosclerotic risk-factor burden at the $2^{\text {nd }}$ test were similar in patients with and without coronary plaque progression. Undetermined residual risks or genetic predisposition may also exist in patients who did not respond to interventions to reduce atherosclerotic risk factors. These non-responders are at considerable risk of further coronary events ${ }^{19)}$.

Residual atherosclerotic plaques in the infarctrelated coronary artery are associated with a greater risk of re-occlusion and may predispose to coronary events at follow-up ${ }^{6)}$. To prevent progression of atherosclerotic plaque in the infarct-related coronary artery, attenuating reperfusion-induced vascular injury and DES-induced endothelial dysfunction may be required in addition to anti-atherosclerotic therapies. We previously showed that the cypher stent inhibited recovery of reperfusion-induced endothelial dysfunction in the infarct-related coronary artery ${ }^{11}$. Second generation stents are currently recommended, as they have less of a suppressive effect on endothelial func- $\operatorname{tion}^{20)}$.

\section{Study Limitations}

First, this study excluded patients with residual organic stenosis ( $>30 \%$ stenosis) or a high constrictor response ( $>30 \%$ from baseline) of the epicardial segment to ACh in the LAD. In addition, the study excluded patients who had new lesions ( $>30 \%$ stenosis) in the LAD during the follow-up period. This exclusion was required because even moderate stenosis $(>30 \%)$ in the conduit coronary artery may increase coronary blood flow in response to $\mathrm{ACh}^{18)}$. Second, risk-factor modification was not optimal for some of present study's patients. However, it was unlikely that insufficient risk-factor reduction was the main cause of plaque progression in the present patients, because the rate of attainment of target levels of risk factors was similar between patients with and without coronary plaque progression. Third, we arbitrarily determined the cut-off value for impaired coronary vasomotor responses from the distribution of these 
responses in control subjects. There are few previous studies using cut-off values for coronary endothelial vasomotor dysfunction. The methods of measuring coronary vasomotor response to ACh vary among studies. Future studies are needed to confirm whether the cut-off values used in this study are appropriate. Fourth, the coronary segment analyzed for epicardial coronary vasomotion by quantitative coronary angiography was not necessarily identical to the segment analyzed for plaque progression by IVUS because of technical issues with quantitative coronary angiography in some patients. Fifth, this study did not analyze the relationship of coronary vasomotor responses with coronary plaque composition. Sixth, approximately $20 \%$ of the patients were excluded after the $1^{\text {st }}$ test. This exclusion may confound the results.

\section{Conclusion}

Persistent impairment of endothelial vasomotor function in the conduit arterial segment and the resistance arteriole was related to atheromatous plaque progression in the infarct-related coronary arteries of STEMI survivors.

\section{Notice of Grant Support}

This research was supported by the Ministry of Education, Culture, Sports, Science, and Technology, Health, Tokyo, Japan (grants-in-aid for B2-19390209 and B-22390158).

\section{Acknowledgment}

None.

\section{Conflicts of Interests}

K.K. has received scholarship donations from Takeda, Daiichi Sankyo, Astellas, Boehringer Ingelheim, MSD, Boston Scientific Japan, Abbott, Medtronic, Biotronik Japan, and ST Jude Medical. The other authors declare no conflicts of interest.

\section{References}

1) Schachinger V, Britten MB and Zeiher AM: Prognostic impact of coronary vasodilator dysfunction on adverse long-term outcome of coronary heart disease. Circulation, 2000; 101: 1899-1906

2) Halcox JP, Schenke WH, Zalos G, Mincemoyer R, Prasad A, Waclawiw MA, Nour KR and Quyyumi AA: Prognostic value of coronary vascular endothelial dysfunction. Circulation, 2002; 106: 653-658

3) Meredith I, Anderson T, Uehata A, Yeung A, Selwyn A and Ganz P: Role of Endothelium in 1schemic Coronary Syndromes. Am J Cardiol, 1993; 72: 27C-31C

4) Vanhoutte PM: Endothelial dysfunction: the first step toward coronary arteriosclerosis. Circ J, 2009; 73: 595601

5) Bonetti PO, Lerman LO and Lerman A: Endothelial dysfunction: a marker of atherosclerotic risk. Arterioscler Thromb Vasc Biol, 2003; 23: 168-175

6) Chen L, Crook JR, Tousoulis D, Chester MR and Kaski JC: Complex stenosis morphology predicts late reocclusion during follow-up after myocardial infarction in patients with patent infarct-related coronary arteries. Am Heart J, 1998; 136: 877-883

7) Okumura K, Yasue H, Matsuyama K, Ogawa H, Morikami Y, Obata K and Sakaino N: Effect of acetylcholine on the highly stenotic coronary artery: Difference between the constrictor response of the infarct-related coronary artery and that of the noninfarct-related artery. Journal of the American College of Cardiology, 1992; 19: 752-758

8) Vita JA, Treasure CB, Nabel EG, McLenachan JM, Fish RD, Yeung AC, Vekshtein VI, Selwyn AP and Ganz P: Coronary vasomotor response to acetylcholine relates to risk factors for coronary artery disease. Circulation, 1990; 81: 491-497

9) Quyyumi AA, Dakak N, Andrews NP, Husain S, Arora S, Gilligan DM, Panza JA and Cannon RO, 3rd: Nitric oxide activity in the human coronary circulation. Impact of risk factors for coronary atherosclerosis. J Clin Invest, 1995; 95: 1747-1755

10) Kugiyama K, Doi H, Motoyama M, Soejima H, Misumi K, Kawano H, Nakagawa O, Michihiro Yoshimura M, Ogawa H, Matsumura T, Sugiyama S, Nakano T, Nakajima $\mathrm{K}$ and Yasue $\mathrm{H}$ : Association of Remnant Lipoprotein Levels With Impairment of Endothelium-Dependent Vasomotor Function in Human Coronary Arteries. Circulation, 1998; 97: 2519-2526

11) Obata JE, Kitta Y, Takano H, Kodama Y, Nakamura T, Mende A, Kawabata K, Saitoh Y, Fujioka D, Kobayashi T, Yano T and Kugiyama K: Sirolimus-eluting stent implantation aggravates endothelial vasomotor dysfunction in the infarct-related coronary artery in patients with acute myocardial infarction. J Am Coll Cardiol, 2007; 50: 1305-1309

12) Obata JE, Nakamura T, Kitta Y, Kodama Y, Sano K, Kawabata K, Saitoh Y, Fujioka D, Kobayashi T, Yano T, Watanabe Y, Watanabe K and Kugiyama K: Treatment of acute myocardial infarction with sirolimus-eluting stents results in chronic endothelial dysfunction in the infarct-related coronary artery. Circ Cardiovasc Interv, 2009; 2: 384-391

13) Ku DD: Coronary vascular reactivity after acute myocardial ischemia. Science, 1982; 218: 576-578

14) VanBenthuysen KM, McMurtry IF and Horwitz LD: Reperfusion after acute coronary occlusion in dogs impairs endothelium-dependent relaxation to acetylcholine and augments contractile reactivity in vitro. J Clin Invest, 1987; 79: 265-274

15) Antman EM, Anbe DT, Armstrong PW, Bates ER, Green LA, Hand M, Hochman JS, Krumholz HM, Kushner FG, Lamas GA, Mullany CJ, Ornato JP, Pearle DL, Sloan MA, Smith SC, Jr., Alpert JS, Anderson JL, Faxon DP, Fuster V, Gibbons RJ, Gregoratos G, Halperin JL, 
Hiratzka LF, Hunt SA, Jacobs AK and American College of Cardiology/American Heart Association Task Force on Practice G: ACC/AHA guidelines for the management of patients with ST-elevation myocardial infarction--executive summary: a report of the American College of Cardiology/American Heart Association Task Force on Practice Guidelines (Writing Committee to Revise the 1999 Guidelines for the Management of Patients With Acute Myocardial Infarction). Circulation, 2004; 110: 588-636

16) Expert Panel on Detection E and Treatment of High Blood Cholesterol in A: Executive Summary of The Third Report of The National Cholesterol Education Program (NCEP) Expert Panel on Detection, Evaluation, And Treatment of High Blood Cholesterol In Adults (Adult Treatment Panel III). JAMA, 2001; 285: 2486-2497

17) Futamata M, Matsuoka $S$, Shimizu T, Yoshizaki T, Obata JE, Nakamura T, Fujioka D, Watanabe Y, Nakamura K, Watanabe K and Kugiyama K: Echolucency of the carotid artery is associated with short-term plaque progression and positive remodeling in the culprit coronary artery in AMI survivors. J Cardiol, 2017; 70: 438-445

18) Gould KL and Lipscomb K: Effects of coronary stenoses on coronary flow reserve and resistance. Am J Cardiol, 1974; 34: 48-55

19) Flammer AJ, Anderson T, Celermajer DS, Creager MA, Deanfield J, Ganz P, Hamburg NM, Luscher TF, Shechter M, Taddei S, Vita JA and Lerman A: The assessment of endothelial function: from research into clinical practice. Circulation, 2012; 126: 753-767

20) Kim JW, Seo HS, Park JH, Na JO, Choi CU, Lim HE, Kim EJ, Rha SW, Park CG and Oh DJ: A prospective, randomized, 6-month comparison of the coronary vasomotor response associated with a zotarolimus- versus a sirolimus-eluting stent: differential recovery of coronary endothelial dysfunction. J Am Coll Cardiol, 2009; 53: 1653-1659 
Supplementary Table 1. Comparisons of Clinical Characteristics between Patients with and without Progaression of Total Atheroma Volume (TAV) in the Infarct-related Coronary Artery

\begin{tabular}{|c|c|c|c|}
\hline & \multicolumn{2}{|c|}{ TAV progression } & \multirow[b]{2}{*}{$p$-value } \\
\hline & With $(n=14)$ & Without $(n=36)$ & \\
\hline Age, years & $63 \pm 14$ & $63 \pm 11$ & 0.99 \\
\hline Sex, male, $n(\%)$ & $9(64.3)$ & $32(88.9)$ & 0.83 \\
\hline Hypertension, $n(\%)$ & $10(71.4)$ & $23(63.9)$ & 0.61 \\
\hline Diabetes mellitus, $n(\%)$ & $3(21.4)$ & $5(13.9)$ & 0.51 \\
\hline \multicolumn{4}{|l|}{ Measurements at the $1^{\text {st }}$ test } \\
\hline BMI $\left(\mathrm{kg} / \mathrm{m}^{2}\right)$ & $25.4 \pm 6.7$ & $24.3 \pm 2.3$ & 0.56 \\
\hline Systolic BP (mmHg) & $104(95-116)$ & $109(100-120)$ & 0.19 \\
\hline $\mathrm{FBG}(\mathrm{mg} / \mathrm{dL})$ & $109(95-119)$ & $95(88-105)$ & 0.62 \\
\hline HbAlc $(\%)$ & $5.9(5.6-6.6)$ & $6.0(5.7-6.3)$ & 0.13 \\
\hline Triglyceride (mg/dL) & $162(135-202)$ & $140(106-173)$ & 0.06 \\
\hline HDL-C $(\mathrm{mg} / \mathrm{dL})$ & $39(34-47)$ & $41(36-50)$ & 0.76 \\
\hline LDL-C (mg/dL) & $134 \pm 28$ & $142 \pm 34$ & 0.42 \\
\hline $\mathrm{CRP}(\mathrm{mg} / \mathrm{dL})$ & $0.3(0.2-1.1)$ & $0.7(0.4-1.1)$ & 0.31 \\
\hline $\mathrm{BNP}(\mathrm{pg} / \mathrm{mL})$ & $158(92-249)$ & $58(29-153)$ & 0.04 \\
\hline $\operatorname{LVEF}(\%)$ & $51 \pm 10$ & $57 \pm 11$ & 0.10 \\
\hline \multicolumn{4}{|l|}{ Measurements at the $2^{\text {nd }}$ test } \\
\hline BMI $\left(\mathrm{kg} / \mathrm{m}^{2}\right)$ & $25.2 \pm 6.4$ & $24.1 \pm 2.3$ & 0.54 \\
\hline Systolic BP (mmHg) & $118(103-136)$ & $117(108-129)$ & 0.75 \\
\hline $\mathrm{FBG}(\mathrm{mg} / \mathrm{dL})$ & $97(91-124)$ & $99(91-110)$ & 0.38 \\
\hline HbAlc (\%) & $6.0(5.8-6.5)$ & $6.0(5.7-6.4)$ & 0.55 \\
\hline Triglyceride (mg/dL) & $179(117-264)$ & $125(92-168)$ & 0.07 \\
\hline HDL-C $(\mathrm{mg} / \mathrm{dL})$ & $43(38-48)$ & $45(38-50)$ & 0.84 \\
\hline LDL-C (mg/dL) & $82 \pm 30^{*}$ & $86 \pm 23^{*}$ & 0.62 \\
\hline $\mathrm{CRP}(\mathrm{mg} / \mathrm{dL})$ & $0.1(0.0-0.5)$ & $0.1(0.0-0.1)^{*}$ & 0.16 \\
\hline $\mathrm{BNP}(\mathrm{pg} / \mathrm{mL})$ & $52(18-158)^{*}$ & $24(15-63)^{*}$ & 0.27 \\
\hline $\operatorname{LVEF}(\%)$ & $55 \pm 13$ & $60 \pm 11$ & 0.19 \\
\hline \multicolumn{4}{|l|}{ Risk status at the $1^{\text {st }}$ test, $n(\%)$} \\
\hline Current smoking & $5(35.7)$ & $17(47.2)$ & 0.46 \\
\hline Pts with $\mathrm{BP}<140 / 90$ & $12(85.7)$ & $30(83.3)$ & 0.84 \\
\hline Pts with HbA1c $<7.0 \%$ & $11(78.6)$ & $32(88.9)$ & 0.30 \\
\hline Pts with LDL-C $<100$ & $2(14.3)$ & $2(5.6)$ & 0.31 \\
\hline \multicolumn{4}{|l|}{ Risk status at the $2^{\text {nd }}$ test, $n(\%)$} \\
\hline Current smoking & $0(0.0)$ & $1(2.8)^{*}$ & 0.53 \\
\hline Pts with $\mathrm{BP}<140 / 90$ & $10(71.4)$ & $30(83.3)$ & 0.10 \\
\hline Pts with $\mathrm{HbA} 1 \mathrm{c}<7.0 \%$ & $11(78.6)$ & $34(94.4)$ & 0.09 \\
\hline Pts with LDL-C $<100$ & $9(64.3)^{*}$ & $28(77.8)^{*}$ & 0.18 \\
\hline \multicolumn{4}{|l|}{ Medications at the $1^{\text {st }}$ test, $n(\%)$} \\
\hline Beta-blocker & $9(64.3)$ & $14(38.9)$ & 0.11 \\
\hline ACE-I/ARB & $10(71.4)$ & $25(69.4)$ & 0.89 \\
\hline Statin & $14(100)$ & $31(86.1)$ & 0.14 \\
\hline Biganide & $0(0.0)$ & $2(5.6)$ & 0.37 \\
\hline Aspirin & $14(100)$ & $36(100)$ & - \\
\hline Thienopyridines & $14(100)$ & $36(100)$ & - \\
\hline \multicolumn{4}{|l|}{ Medications at the $2^{\text {nd }}$ test, $n(\%)$} \\
\hline Beta-blocker & $9(64.3)$ & $15(41.7)$ & 0.15 \\
\hline ACE-I/ARB & $13(92.9)$ & $26(72.2)$ & 0.11 \\
\hline Statin & $14(100)$ & $34(94.4)$ & 0.37 \\
\hline Biganide & $0(0.0)$ & $2(5.6)$ & 0.37 \\
\hline Aspirin & $14(100)$ & $35(97.2)$ & 0.53 \\
\hline Thienopyridines & $14(100)$ & $36(100)$ & - \\
\hline \multicolumn{4}{|l|}{ AMI variables } \\
\hline Peak CPK (IU/L) & $2808 \pm 1739$ & $3112 \pm 2357$ & 0.66 \\
\hline Use of BMS, $n(\%)$ & $4(28.6)$ & $7(19.4)$ & 0.48 \\
\hline Use of $1^{\text {st }}$ generation DES, $n(\%)$ & $1(7.1)$ & $7(19.4)$ & 0.51 \\
\hline Use of $2^{\text {nd }}$ generation DES, $n(\%)$ & $9(64.3)$ & $22(61.1)$ & 0.65 \\
\hline Stent length $(\mathrm{mm})$ & $28.7 \pm 12.6$ & $23.8 \pm 11.2$ & 0.16 \\
\hline MLD after stenting (mm) & $2.9 \pm 0.5$ & $3.1 \pm 0.4$ & 0.19 \\
\hline
\end{tabular}

Data are expressed as the mean \pm S.D, median (25th-75th percentiles) or the number $(\%)$ of patients. ${ }^{*} p<0.05$ vs. the respective value at the $1^{\text {st }}$ test. TAV, total atheroma volume; Pts, patients; BMI, body mass index; BP, blood pressure; FBG, fasting blood glucose; HbA1c, hemoglobin A1c; HDL-C, high-density lipoprotein cholesterol; LDL-C, low-density lipoprotein cholesterol; BNP, brain natriuretic peptide; CRP, C-reactive protein; LVEF, left ventricular ejection fraction; BP, blood pressure; ACE-I, angiotensin converting enzyme inhibitor; ARB, angiotensin II receptor blocker; AMI, acute myocardial infarction; CPK, creatine phosphokinase; PCI, percutaneous coronary intervention; BMS, bare metal stent; DES, drug eluting stent; MLD, minimal lumen diameter. 